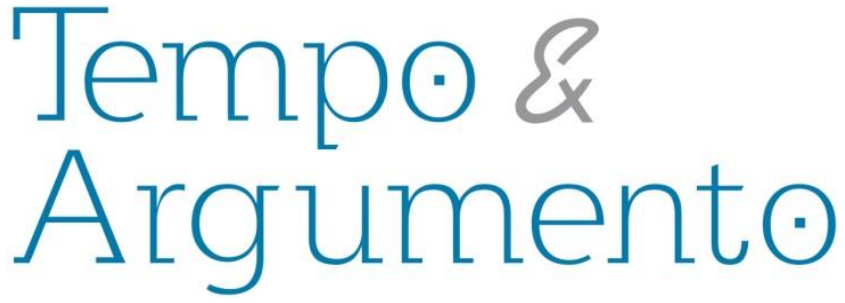

\title{
Caminhos e descaminhos do pensamento cultural na historiografia da diáspora africana
}

\section{Resenha da obra:}

MARCUSSI, Alexandre Almeida. Diagonais do afeto: teorias do intercâmbio cultural nos estudos da diáspora africana. São Paulo: Intermeios/Fapesp, 2016. 258p.

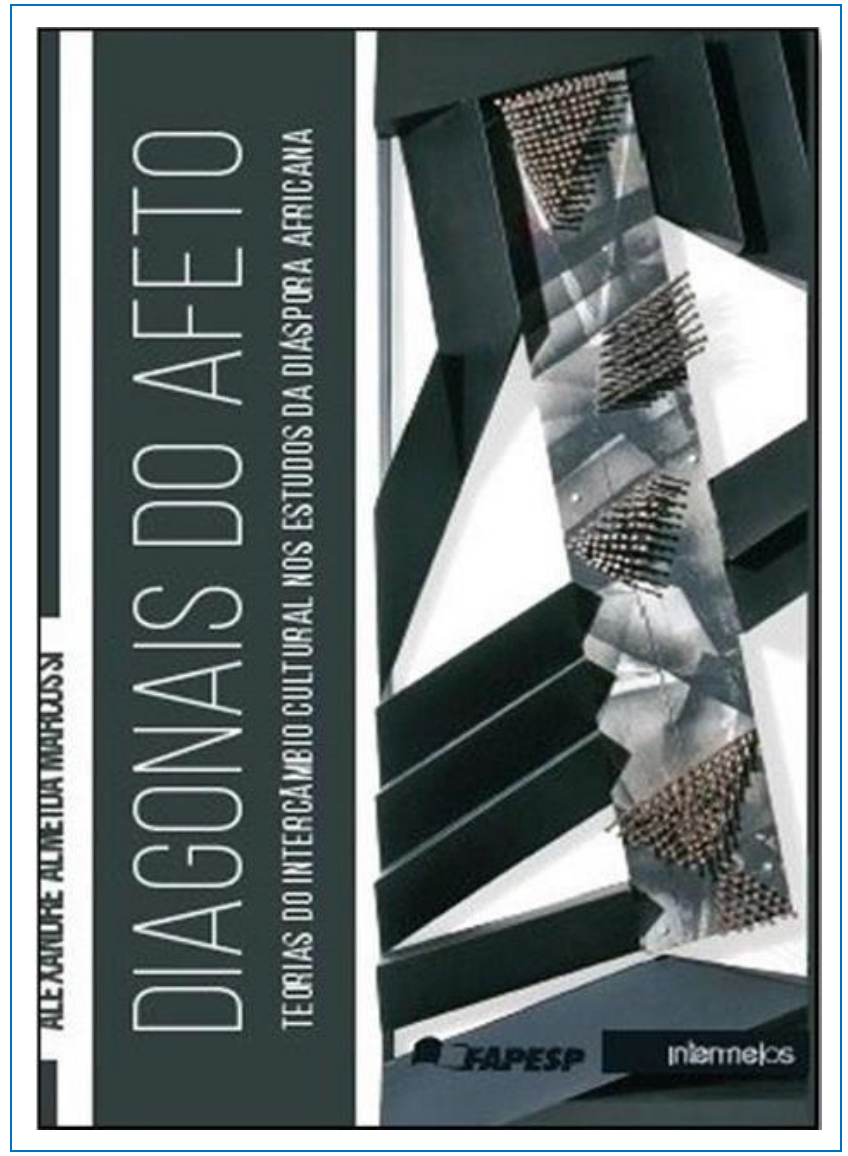

Autor da resenha

\section{Bruno Pinheiro}

Doutorando em História na Universidade

Estadual de Campinas (Unicamp). Brasil s1dbpinheiro@gmail.com

\section{Para citar esta resenha:}

MARCUSSI, Alexandre Almeida. Diagonais do afeto: teorias do intercâmbio cultural nos estudos da diáspora africana. São Paulo: Intermeios/Fapesp, 2016. 258p. Resenha de: PINHEIRO, Bruno. Caminhos e descaminhos do pensamento cultural na historiografia da diáspora africana. Revista Tempo e Argumento, Florianópolis, v. 9, n. 22, p. 487 - 493. set./dez. 2017. 
O livro Diagonais do Afeto: teorias do intercâmbio cultural nos estudos da diáspora africana, de 2016, é resultado da dissertação de mestrado defendida em 2010 por Alexandre Almeida Marcussi, hoje professor de História da África na Universidade Federal de Minas Gerais. Nessa pesquisa, ele toma como objeto de análise os modelos interpretativos da Antropologia Cultural acerca do contato entre diferentes populações que se tornaram definidores dos debates sobre a ideia de cultura afro-americana na historiografia da diáspora. Nos quatro capítulos, Marcussi realiza, a partir de uma seleção de textos-chave publicados ao longo do século XX, uma genealogia dos conceitos popularizados nessa literatura, localizando os processos de continuidade e descontinuidade de suas operações lógicas e as contradições em seus usos.

No primeiro capítulo, As armadilhas da cultura, são apresentados os enunciados propostos por Franz Boas que permitiram a formação de uma concepção culturalista de intercâmbio cultural. É também avaliada a reelaboração desses argumentos nos estudos afro-americanos de Melville J. Herskovits, a partir da análise do ensaio O mito do passado negro (1941), e os limites de seus pressupostos, evidenciados a partir de seus debates com o sociólogo negro Edward Franklin Frazier. Para tal fim, Marcussi parte de um esquema produzido por Boas acerca das relações de contato nas quais elementos da cultura nativa passariam por processos simultâneos de permanência e mudança. Nessa relação, seria estável o "espírito" de cada povo, ideia associada a um sentido indivisível e imanente às culturas. Essa noção, frente à experiência histórica de cada contato, definiria o que seria passível de ser transformado, mediando a operação entendida por Boas como aculturação. Essa postura, ao mesmo tempo essencialista e historicizante, se apresenta na leitura de Marcussi como um importante alicerce das interpretações da cultura afroamericana, de modo que sua longa permanência se configura como um problema central do livro.

$\mathrm{Na}$ busca por entender os usos dos termos boasianos no estabelecimento dos Estudos Afro-Americanos, Marcussi analisa o livro O mito do passado negro de Herskovits. Esse texto foi uma resposta direta à ideologia dominante no debate acadêmico norteamericano daquele período, que sugeria que os negros dos Estados Unidos haviam abandonado sua herança cultural africana e se tornado, assim, sujeitos sem passado. $O$ 
autor refuta essa hipótese, produzindo uma escala das diferentes relações das culturas afro-americanas com sua herança cultural, cujas balizas seriam a aculturação e a africanização. Um dado fundamental para classificar uma comunidade nessa gradação seria o contato entre negros e brancos em seu interior, de modo que, quanto mais concentrados os indivíduos de ascendência africana, mais africanizada seria a comunidade. Enquanto essa razão numérica era produzida por circunstâncias históricas, as transformações determinadas pelo "espírito" ocorreriam ora na "aparência exterior" de sua manifestação, ora em suas “qualidades imanentes”. Marcussi entende esse esquema como uma reelaboração daquele produzido por Boas, sendo que, em Herskovits, permanência e mudança poderiam ser entendidas como imbricadas em um mesmo processo cultural, compondo formas intermediárias de aculturação.

A ideologia que $O$ mito do passado negro buscava desarticular tinha adesão de intelectuais negros norte-americanos em sua época, sendo utilizada como forma de defesa frente a retórica ainda popular do evolucionismo, que associava esse passado à ideia de barbárie. Marcussi identifica o problema da assimilação das populações negras à sociedade estadunidense como questão central da disputa entre Frazier e Herskovits na década de 1940. Ao localizar as culturas afro-americanas como autóctones, resultantes da total desagregação das formas básicas de organização social reconhecidas pelas populações escravizadas, Frazier as opõe à ideia herskovitsiana de que um "espírito" africano guiaria as ações das comunidades negras americanas. A concepção culturalista de Herskovits, levada a seu limite, permitiria interpretar as ações dessas populações como guiadas por valores estranhos à cultura euroamericana, inviabilizando qualquer debate sobre integração.

Em seu segundo capítulo, Ambiguidades da crioulização, Marcussi avança três décadas para, a partir do ensaio O nascimento da cultura afro-americana (1973) dos antropólogos Sidney Mintz e Richard Price, analisar a incorporação do conceito de crioulização à tradição boasiana. Em sua retórica culturalista, a crioulização assume o lugar que era ocupado pela ideia de aculturação, ainda que ela não seja uma categoria expressa textualmente, apresentando-se apenas como uma operação lógica. Na medida em que, numa primeira leitura, essa substituição sugira uma descontinuidade, Marcussi a 
entende como uma tentativa de resolver determinadas limitações e contradições presentes nessa vertente teórica. Desse modo, os conceitos herskovitsianos são rearranjados, numa perspectiva a partir da qual as culturas afro-americanas possam ser entendidas como, simultaneamente, africanas e americanas, ainda que, em seu “espírito”, se mantenham essencialmente associadas à primeira filiação.

$\mathrm{Na}$ interpretação das culturas afro-americanas de Mintz e Price, sobrepoem-se dois modelos apresentados como complementares: o argumento demográfico, de origem culturalista, e o sociorrelacional, de matriz sociológica. No primeiro, os autores retomam a leitura de Herskovits sobre a proporção entre negros e brancos na determinação do nível de aculturação de uma comunidade, deslocando o foco para o grau de concentração de sujeitos de cada grupo étnico africano. No segundo, os autores propõem que os contextos institucionais, sejam eles sociais, políticos ou de parentesco, devam ser tomados como modeladores dos processos culturais. A presença dos conceitos culturalistas e sociológicos produz contradições internas no texto que são assumidas por Mintz e Price como necessárias frente à natureza dinâmica dos fenômenos culturais. Esse fato é identificado por Marcussi como um dos motivos centrais das polêmicas em torno da publicação.

No terceiro capítulo, O retorno à cultura, o autor trata da recepção de 0 nascimento da cultura afro-americana na historiografia da diáspora africana produzida a partir da década de 1980. Nas críticas realizadas a Mintz e Price por pesquisadores como John Thornthon (1992), Douglas Chambers (2001), Paul Lovejoy e David Trotman (2002) e James Sweet (2003), Marcussi evidencia um padrão no qual a interlocução é realizada a partir do vocabulário culturalista, ao passo que o argumento sociológico é minimizado ou desconsiderado. O antagonismo desses autores revela-se especialmente na ênfase dada aos processos de continuidade e descontinuidade no interior das culturas afroamericanas. Enquanto os dois antropólogos ressaltavam a criatividade dos africanos da diáspora em reinventar seus universos simbólicos em ambientes adversos, seus críticos valorizavam os modos de resistência que levaram os sujeitos à manutenção de suas culturas. Essas diferentes posturas são assinaladas por Marcussi como diretamente ligadas às filiações de cada um com os debates públicos em torno do racismo e dos 
movimentos negros. Em um texto publicado em 1999, Price respondeu a muitas das polêmicas geradas pelo ensaio de 1973, privilegiando a retórica culturalista. Marcussi interpreta essa como uma tendência da historiografia da diáspora africana, ressaltando o predomínio de concepções essencialistas de cultura em sua literatura recente.

No último capítulo, Afeto e ambivalência, Marcussi recua no tempo e retoma duas publicações de matriz boasiana, Contraponto cubano do tabaco e do açúcar (1940) de Fernando Ortiz e Casa grande e senzala (1933) de Gilberto Freyre. Neles, ele evidencia os usos da retórica culturalista pelos dois autores, e, a partir da aproximação com textos ligados ao pensamento pós-colonial, sintetiza soluções para as contradições dessa tradição teórica presentes nos estudos sobre a diáspora. Do primeiro, Marcussi examina o conceito de transculturação, proposto como alternativo a aculturação. Ela se diferencia ao prever, nas relações de contato, transformações nos dois sentidos, que Ortiz exemplifica numa narrativa pouco ortodoxa sobre a introdução do tabaco na Europa. Para o autor cubano, os sentidos da planta, ligados num primeiro momento à religiosidade ameríndia, teriam sido reimaginados frente ao julgo eclesiástico e, em seguida, ao desejo de intelectuais humanistas em transgredir a ordem cristã. Para Marcussi, a transculturação de Ortiz é guiada por relações de afeto identificadas como desejo e tentação. Ao abordar Casa Grande \& Senzala, o argumento da mestiçagem realizado por Freyre é apresentado a partir da posição central assumida pelas relações sociais no interior do latifúndio escravista, que aproximariam os elementos antagônicos do Brasil colonial de modo que os potenciais conflitos originados pelas relações de desigualdade étnico-racial seriam apaziguados. No cerne dessa interpretação, estaria o intercurso sexual entre homens brancos e mulheres indígenas e negras, realizado muitas vezes de modo forçado. Esse seria definidor de uma estrutura de afetos que aproximam prazer e violência.

A partir do debate sobre os afetos em Ortiz e Freyre, Marcussi realiza aproximações improváveis com outros textos de autores ligados ao pensamento póscolonial. Ao desejo violento descrito por Freyre, Marcussi aproxima as estruturas afetivas delineadas por Franz Fanon em Pele negra, máscaras brancas (1952), no qual são descritas as violências decorrentes das hierarquias raciais socialmente naturalizadas, presentes em 
relações interpessoais. Apesar de os dois autores assumirem atitudes diametralmente opostas frente ao fenômeno - Freyre o interpretando como a pedra de toque de um projeto nacional, e Fanon como um obstáculo para a emancipação de negros e brancos ambos operam uma transposição dessa relação do foro íntimo ao plano da política. Marcussi associa essa lógica, entendida como metonímia de uma relação histórica de interdependência entre Europa e África, à análise dos processos coloniais realizada por Homi Bhabha em O Lugar da Cultura (1994). Em Bhabha, a cultura nesses contextos resultaria em um espaço comum em que as partes se redefiniriam mutuamente e constantemente, invalidando a ideia essencialista de cultura presente na tradição boasiana. Marcussi finaliza o capítulo conectando as pontas entre esses autores utilizando o trabalho de Robert Young, Desejo Colonial (1995). Young localiza nos debates públicos acerca das empreitadas coloniais europeias da segunda metade do século XIX uma centralidade dos atos sexuais compulsórios como mediadores de sua efetivação, prática defendida por Joseph Arthur de Gobineau, um dos principais teóricos do racialismo, em seu Ensaio sobre a desigualdade das raças humanas (1853). Desse modo, Marcussi insere ao debate das trocas culturais as especificidades próprias à condição de colonialidade.

Ao concentrar-se nas operações lógicas presentes nos textos, localizando-as apenas pontualmente acerca de seus contextos de produção e circulação, a análise de Marcussi é por vezes lacunar. Esse tipo de aproximação traria contribuições para se entenderem as assimetrias em relação aos contextos institucionais em que as publicações analisadas foram lidas, desvendando particularidades da produção de conhecimento sobre a diáspora africana. Apesar disso, Diagonais do Afeto: teorias do intercâmbio cultural nos estudos da diáspora africana apresenta uma leitura bastante acurada da orientação culturalista nos estudos sobre o tema. Ao propor uma integração do pensamento póscolonial a essas interpretações, ele apresenta um deslocamento salutar para as práticas historiográficas associadas às populações negras e as relações raciais. 
Recebido em 08/11/2017

Aprovado em 25/11/2017

Universidade do Estado de Santa Catarina - UDESC

Programa de Pós-Graduação em História - PPGH

Revista Tempo e Argumento

Volume 09 - Número 22 - Ano 2017

tempoeargumento@gmail.com 